\title{
Hyperprolactinemia in Children with Subclinical Hypothyroidism
}

\author{
Neera Sharma ${ }^{1}$, Deep Dutta ${ }^{2,3}$, Lokesh Kumar Sharma ${ }^{1}$ \\ ${ }^{1}$ Dr. Ram Manohar Lohia Hospital and Post Graduate Institute of Medical Education and Research, Department of Biochemistry, New Delhi, India \\ ${ }^{2}$ Venkateshwar Hospital, Clinic of Diabetes, Endocrinology and Metabolic Disorder, New Delhi, India \\ ${ }^{3}$ Dr. Ram Manohar Lohia Hospital and Post Graduate Institute of Medical Education and Research, Department of Endocrinology, New Delhi, \\ India
}

\section{What is already known on this topic?}

Hyperprolactinemia is common in adults with subclinical and overt primary hypothyroidism. Hyperprolactinemia in children has been linked to adverse metabolic outcomes. Prevalence of hyperprolactinemia in children with thyroid dysfunction, especially subclinical hypothyroidism, is not known.

\section{What this study adds?}

Hyperprolactinemia is common in children with hypothyroidism, observed in a third of children with subclinical hypothyroidism and more than half of children with overt hypothyroidism. Receiver operating characteristics analysis showed that thyroid-stimulating hormone $\geq 4.00 \mathrm{mIU} / \mathrm{L}$ has a good sensitivity and specificity in predicting hyperprolactinemia in children. Hyperprolactinemia may be an indication for treating subclinical hypothyroidism in children.

\begin{abstract}
Prevalence of hyperprolactinemia in children with subclinical hypothyroidism $(\mathrm{ScH})$ is not known. This study aimed to determine the occurrence and predictors of hyperprolactinemia in euthyroid children and in children with $\mathrm{ScH}$ and overt primary hypothyroidism $(\mathrm{OPH})$. Serum prolactin levels were estimated in consecutive children $<18$ years of age undergoing thyroid function evaluation and diagnosed to have normal thyroid function, $\mathrm{ScH}$, or OPH. Children with pituitary adenomas, secondary hypothyroidism, multiple pituitary hormone deficiency, comorbid states, and drug-induced hyperprolactinemia were excluded. From the initially screened 791 children, hormonal data from 602 children who fulfilled all criteria were analyzed. Seventy-one (11.79\%) of these had ScH, and 33 $(5.48 \%)$ had OPH. Occurrence of hyperprolactinemia was highest in the OPH group (51.51\%), followed by ScH (30.98\%) and euthyroid children $(4.41 \%)(\mathrm{p}<0.001)$. Median $\left(25^{\text {th }}-75^{\text {th }}\right.$ percentiles $)$ levels for prolactin in euthyroid, ScH, and OPH children were $13.3(9.4-$ 17.95), 19.15 (15.97-30.12), and $28.86(17.05-51.9) \mathrm{ng} / \mathrm{mL}$, respectively $(\mathrm{p}<0.001)$. In children, prolactin levels were comparable in males and females. An age-related increase in serum prolactin was noted in euthyroid children, which was statistically significant in postpubertal (16-18 years) children. Area under the curve for thyroid stimulating hormone (TSH) in predicting hyperprolactinemia in children was 0.758 (95\% confidence interval: $0.673-0.829 ; \mathrm{p}<0.001$ ). TSH $\geq 4.00 \mathrm{mIU} / \mathrm{L}$ had a sensitivity of $69.4 \%$ and specificity of $77.6 \%$ in detecting hyperprolactinemia. Hyperprolactinemia is common in children with ScH and OPH. TSH $\geq 4.00 \mathrm{mIU} / \mathrm{L}$ has a good sensitivity and specificity in predicting hyperprolactinemia in children. More studies are needed to establish if hyperprolactinemia should be an indication for treating $\mathrm{ScH}$ in children.
\end{abstract}

Keywords: Subclinical hypothyroidism, hyperprolactinemia, prolactin, thyroid stimulating hormone

Address for Correspondence: Deep Dutta MD,

Venkateshwar Hospital, Department of Diabetes, Endocrinology and Metabolic Disorder, New Delhi, India

Phone: +919911544096 E-mail: deepdutta2000@yahoo.com ORCID ID: orcid.org/0000-0003-4915-8805

'Copyright 2017 by Turkish Pediatric Endocrinology and Diabetes Society

The Journal of Clinical Research in Pediatric Endocrinology published by Galenos Publishing House.
Conflict of interest: None declared Received: 31.03 .2017 Accepted: 19.05 .2017 


\section{Introduction}

Hyperprolactinemia is a common endocrinopathy encountered in clinical practice with a prevalence ranging from $0.4 \%$ to $5 \%$ (1). We recently reported that in a cohort of 2848 individuals, hyperprolactinemia was common in patients with subclinical hypothyroidism $(\mathrm{ScH})$, especially in those with thyroid stimulating hormone (TSH) $>7.5 \mathrm{mIU} / \mathrm{L}$ (2). TSH $\geq 7.51 \mathrm{mIU} / \mathrm{L}$ (females) and $\geq 8.33 \mathrm{mIU} / \mathrm{L}$ (males) had a sensitivity of $\approx 50 \%$ with a high specificity of $>90 \%$ in detecting hyperprolactinemia (2). Overt hypothyroidism in children has been linked with pituitary enlargement, pituitary hyperplasia, and in rare cases, even with feedback pituitary adenoma and multiple pituitary hormone deficiency $(3,4)$. This enlargement of the pituitary is primarily believed to be due to increase in the number and size of thyrotrophs and lactotrophs in the pituitary gland (3). Primary hypothyroidism leads to increased thyrotropin-releasing hormone (TRH) release from hypothalamus, which has a physiologic trophic effect on thyrotrophs and lactotrophs resulting in increased TSH and prolactin levels, respectively $(3,5)$. Reduced prolactin clearance as well as reduced sensitivity to the inhibitory actions of dopamine and its agonists on prolactin release also contribute to hyperprolactinemia (6). However, prolactin levels have rarely been investigated in children with hypothyroidism, especially in those with $\mathrm{ScH}$. Also, the prevalence of hyperprolactinemia in children with $\mathrm{ScH}$ is not known. Hence, the aim of this study was to determine the occurrence and predictors of hyperprolactinemia in children with a spectrum of thyroid dysfunction ranging from euthyroidism to $\mathrm{ScH}$ and overt primary hypothyroidism.

\section{Methods}

Consecutive children younger than 18 years undergoing thyroid function evaluation at the department of biochemistry were selected for investigation. Children diagnosed to have pituitary adenomas, secondary hypothyroidism, multiple pituitary hormone deficiency, subclinical hyperthyroidism, and overt hyperthyroidism were excluded. Also, children with associated comorbidities such as chronic liver disease, renal disease, syndromes, and those taking medications such as anti-epileptics, neuroleptics, and anti-psychotics were excluded. The study protocol was explained, and only those children or their parents/guardians who gave informed written consent were included in the study. Serum prolactin was assayed from samples of children undergoing thyroid function evaluation who fulfilled the above criteria and who were diagnosed to have either $\mathrm{ScH}$, overt primary hypothyroidism, or normal thyroid function. The reference range of free tri- iodothyronine (FT3), free tetra-iodothyronine (FT4), and TSH in our laboratory is $2-4.4 \mathrm{pg} / \mathrm{mL}, 0.6-2.2 \mathrm{ng} / \mathrm{dL}$, and 0.5-5 mIU/L, respectively. ScH was defined as normal FT4 levels with TSH levels above the normal range (7). Overt primary hypothyroidism was defined as TSH levels above the normal range accompanied by low FT4 levels (7). Serum was separated from samples collected and stored at -80 ${ }^{\circ} \mathrm{C}$. Patients with drug-induced hyperprolactinemia were excluded. The study duration was from August 2014 to December 2016. The Institutional Ethics Committee of Dr. Ram Manohar Lohia Hospital and Post Graduate Institute of Medical Education and Research approved the study [approval number: 89 (13/2014/IEC/PGIMER/RML/1645) dated $11^{\text {th }}$ June 2014]. Serum prolactin was measured using chemiluminescence microparticle immunoassay (CLIA) (VITROS $^{\circledast}$ ECiQ Immunodiagnostic System, Johnson \& Johnson, USA), a methodology which has been elaborated elsewhere (2). The normal ranges of serum prolactin in adults are $2.8-27 \mathrm{ng} / \mathrm{mL}$ in females and $2.1-17 \mathrm{ng} / \mathrm{mL}$ in males (2). We used the age- and sex-specific normal ranges of serum prolactin in children developed by Aitkenhead and Heales (8) for defining hyperprolactinemia in our study. There is no sex difference in serum prolactin among children till 1 year of age. All children 16 years old or younger, with serum prolactin levels higher than the upper limit $\left(97^{\text {th }}\right.$ percentile) for their age and sex were defined to have hyperprolactinemia (Table 1). For children between 16 and 18 years of age, the adult reference range was used in the analysis. Hence, hyperprolactinemia among children in the 16-18 years old group was defined as a serum prolactin level $>27 \mathrm{ng} / \mathrm{mL}$ in females and $>17 \mathrm{ng} /$ $\mathrm{mL}$ in males (2).

\begin{tabular}{|c|c|c|}
\hline \multirow[t]{2}{*}{ Age group } & \multicolumn{2}{|c|}{$\begin{array}{l}\text { Serum prolactin levels (ng/mL) (mean } \\
\text { values and ranges) }\end{array}$} \\
\hline & Males & Females \\
\hline 0-30 days & $31.35-236.50$ & $31.35-236.50$ \\
\hline 31-60 days & $24.0-147.40$ & $24.0-147.40$ \\
\hline 61-90 days & $5.08-98.70$ & $5.08-98.70$ \\
\hline 3-5 months & $3.76-98.50$ & $3.76-98.50$ \\
\hline 6-8 month & $4.04-77.41$ & $4.04-77.41$ \\
\hline 9-12 months & $4.98-38.54$ & $4.98-38.54$ \\
\hline $1-2$ years & $3.05-37.08$ & $3.15-40.65$ \\
\hline 2-4 years & $2.67-33.69$ & $2.63-30.08$ \\
\hline $5-8$ years & $2.20-20.58$ & $2.11-21.90$ \\
\hline 9-11 years & $1.88-26.08$ & $2.06-25.75$ \\
\hline 12-16 years & $2.06-22.51$ & $2.72-28.30$ \\
\hline
\end{tabular}


The VITROS ${ }^{\circledR}$ ECiQ Immunodiagnostic System, Johnson \& Johnson, USA was also used for estimation of FT3, FT4, and TSH. The methodology has been elaborated elsewhere (9). Samples from children having elevated prolactin levels with normal thyroid function were evaluated for macroprolactinemia using polyethylene glycol (PEG) precipitation test (treatment of equal parts of serum with PEG followed by centrifugation) to remove macroprolactin. Macroprolactinemia was diagnosed if post-PEG prolactin level was $<40 \%$ of pre-PEG levels (10).

\section{Statistical Analysis}

Normality of the distribution of variables was assessed using the Kolmogorov-Smirnov test, and accordingly parametric or nonparametric tests were used for statistical analysis. The receiver operating characteristics (ROC) curves were plotted, and areas under the curves (AUCs) with $95 \%$ confidence interval (CI) were calculated to explore the diagnostic efficacy and determine cutoffs of serum TSH in predicting hyperprolactinemia in children. The Youden index, defined as (sensitivity + specificity) -1 was used to determine the optimal cut-off points. A p-value $<0.05$ was considered statistically significant. SPSS version 20 was used for the analyses.

\section{Results}

Of a total of 791 children younger than 18 years of age who underwent thyroid function evaluation, 649 (males:females $=200: 402$ ) who fulfilled all inclusion and exclusion criteria had their serum prolactin levels determined. Drug-induced hyperprolactinemia was diagnosed in 47 children who were excluded. Other reasons for exclusion were secondary hypothyroidism $(n=23)$, multiple pituitary hormone deficiency $(n=16)$, associated pituitary adenoma $(n=12)$, comorbid disease states $(n=85)$, and refusal to consent $(n=6)$. Hence, 602 children were evaluated in the study. Of these, 71 children $(11.79 \%)$ were diagnosed to have $\mathrm{ScH}$ and 33 (5.48\%) had overt primary hypothyroidism. The remaining 498 children were euthyroid. The occurrence of hyperprolactinemia in subclinically hypothyroid and overt hypothyroid children was $22(30.98 \%)$ and $17(51.51 \%)$, respectively, figures which were significantly higher as compared to euthyroid children $(4.41 \%)(p<0.001)$. Among the 71 children with $\mathrm{ScH}$, the occurrence of hyperprolactinemia in children with TSH levels of 5-7.5, 7.5-10, and $>10 \mathrm{mIU} / \mathrm{L}$ was $23.80 \%$ (15/63), $80 \%$ (4/5), and $100 \%$ (3/3), respectively ( $<<0.001)$. Median $\left(25^{\text {th }}-75^{\text {th }}\right.$ percentile) values for serum prolactin levels in euthyroid children, children with $\mathrm{ScH}$, and those with overt primary hypothyroidism were 13.3 (9.4-17.95) $\mathrm{ng} / \mathrm{mL}, 19.15$ (15.97-30.12) ng/mL, and 28.86 (17.05-51.9) $\mathrm{ng} / \mathrm{mL}$, respectively $(\mathrm{p}<0.001)$.
Among the 602 children evaluated in this study, 33 were in age group 0-5 years, 54 in age group 6-10 years, 211 in age group 11-15 years, and 304 in age group 16-18 years (Table 2). Median prolactin levels among children in the different age groups (euthyroid vs. hypothyroidism) are shown in Table 3. As shown in Table 3, serum prolactin levels increased with age in euthyroid children, an increase which was significantly higher in the post-pubertal (16-18 years) age group $(p<0.001)$. A similar trend was not seen in children with hypothyroidism (Table 3). Median prolactin levels of children in the different age groups were not significantly different based on the sex of the child (Table 4). The areas under the ROC curves were constructed to evaluate the predictive values of serum TSH in predicting hyperprolactinemia in children. The AUC for TSH in predicting hyperprolactinemia in children was $0.758(95 \%$ CI: $0.673-0.829 ; p<0.001)$. A serum TSH $\geq 4.00 \mathrm{mIU} / \mathrm{L}$ had a sensitivity of $69.4 \%$ and specificity of $77.6 \%$ in detecting hyperprolactinemia (Figure 1).

\section{Discussion}

Undiagnosed and untreated hyperprolactinemia has been linked with poor bone mineral health, osteomalacia, hypogonadotropic hypogonadism, menstrual abnormalities, and ovulatory dysfunction in adults $(11,12)$.

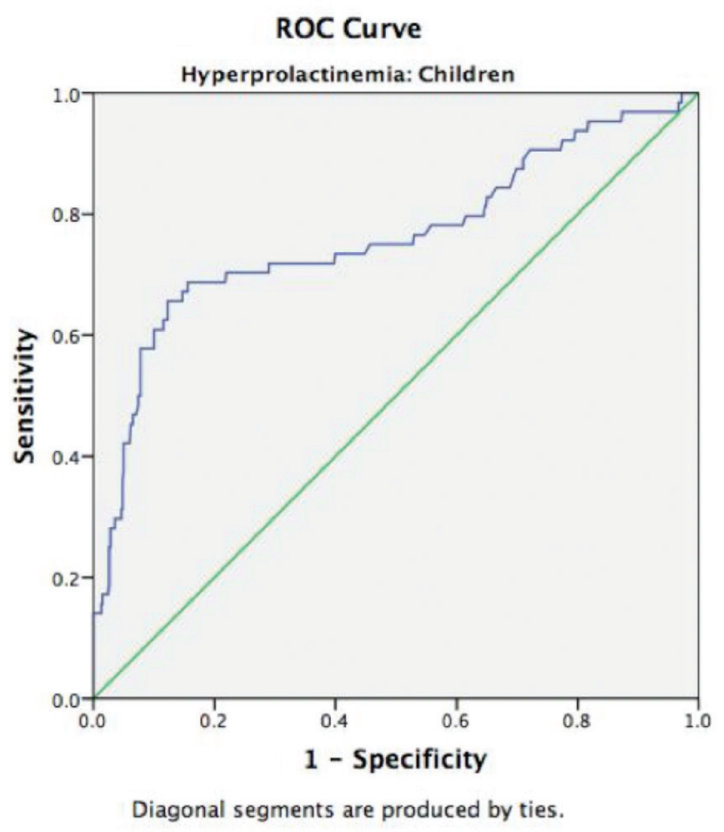

Figure 1. Receiver operating characteristics curve (blue line) showing the sensitivity and specificity of serum thyroid stimulating hormone in predicting hyperprolactinemia in children

ROC: receiver operating characteristics 
Hyperprolactinemia is believed to be rare in children (13). Drug-induced hyperprolactinemia secondary to anti-epileptics, antipsychotics, and hyperprolactinemia secondary to pituitary tumors are believed to be the most common causes of hyperprolactinemia in children $(14,15)$. Hyperprolactinemia in children has also been linked with impaired bone health, puberty problems, galactorrhea in females, and gynecomastia in males $(16,17)$.

Our study highlighted for the first time that hyperprolactinemia is common in children with $\mathrm{ScH}$ $(30.98 \%)$. The occurrence of hyperprolactinemia in children with overt hypothyroidism in this study was $51.51 \%$ and its occurrence in euthyroid children was $4.41 \%$. These trends are similar to those observed in adults. We have previously reported the occurrence of hyperprolactinemia in adults with euthyroidism, $\mathrm{ScH}$, and overt hypothyroidism to be 2.02$2.32 \%, 31.61-35.65 \%$, and $39.53-42.95 \%$, respectively (2).

An important observation of this study was that in contrast to adults (females have higher prolactin levels than males), no difference in prolactin levels was noted between male and female children. Prolactin levels in post-pubertal children (16-18 years of age) were significantly higher compared to prepubertal (0-5 years, 6-10 years) and peri-pubertal children (11-15 years). Increased sex steroid levels in the post-pubertal state, especially estrogen, may explain this finding. The trophic effect of estrogen on TRH-mediated prolactin secretion from lactotrophs has been reported in various studies (18).

A serum TSH level $\geq 4.00 \mathrm{mIU} / \mathrm{L}$ had a sensitivity and specificity of $69.4 \%$ and $77.6 \%$, respectively in detecting hyperprolactinemia in children. We have previously demonstrated that TSH levels of $\geq 7.51 \mathrm{mIU} / \mathrm{L}$ in females and $\geq 8.33 \mathrm{mIU} / \mathrm{L}$ in males can be used as cut-off levels in detecting hyperprolactinemia in adults (2). There is often a lack of clarity among doctors with regard to indications for levothyroxine therapy in $\mathrm{ScH}$ (19). Hyperprolactinemia may be accepted as one of the indications for levothyroxine therapy in adults with $\mathrm{ScH}(2)$.

This study highlighted that the TSH thresholds for detecting hyperprolactinemia is much lower in children as compared to adults (4 mIU/L vs. $7.5 \mathrm{mIU} / \mathrm{L}$ ). This statement is also supported by the observation that in our study, all children with $\mathrm{ScH}$ who had TSH levels $\geq 7.51 \mathrm{mIU} / \mathrm{L}$ had hyperprolactinemia as compared to only 49-61\% of adults reported in a previous study (2). The limitations of this study include the lack of

Table 2. Occurrence of subclinical and overt primary hypothyroidism in children of different age groups in this study

\begin{tabular}{llll}
\hline Age group & Euthyroid & Subclinical hypothyroidism & Overt primary hypothyroidism \\
\hline $0-5$ years $(n=33)$ & 21 & 6 & 6 \\
6-10 years $(n=54)$ & 46 & 6 & 2 \\
$11-15$ years $(n=211)$ & 184 & 17 & 10 \\
$16-18$ years $(n=304)$ & 247 & 42 & 15 \\
\hline
\end{tabular}

Table 3. Serum prolactin levels in euthyroid children as compared to those with subclinical or overt hypothyroidism in different age groups (median and $25^{\text {th }}-75^{\text {th }}$ percentile values)

\begin{tabular}{|c|c|c|c|}
\hline \multirow[b]{2}{*}{ Age group } & \multicolumn{2}{|c|}{ Serum prolactin levels (ng/mL) } & \multirow[t]{2}{*}{$\mathrm{p}$} \\
\hline & Euthyroid & Hypothyroid (subclinical or overt) & \\
\hline $0-5$ years $(n=33)$ & $10.05[5.87-13.98](n=21)$ & $26.5[19.17-43.30](n=12)$ & $<0.001$ \\
\hline $6-10$ years $(n=54)$ & $10.45[8.22-14.95](n=46)$ & $18.35[15.98-33.75](n=8)$ & $<0.001$ \\
\hline $11-15$ years $(n=211)$ & $10.75[7.45-16.25](n=184)$ & $17.5[15.1-43.0](n=27)$ & $<0.001$ \\
\hline $16-18$ years $(n=304)$ & $15.0[11.1-20.2](n=247)$ & $23[16-30](n=57)$ & $<0.001$ \\
\hline
\end{tabular}

Table 4. Median prolactin levels in male and female children of different age groups (median and $25^{\text {th }}-75^{\text {th }}$ percentile values)

\begin{tabular}{llll}
\hline Age group & \multicolumn{2}{c}{ Serum prolactin levels $(\mathrm{ng} / \mathrm{mL})$} & \\
\cline { 2 - 3 } & Males & Females & $\mathrm{p}$ \\
\hline 0-5 years $(\mathrm{n}=33)$ & $16.33[14.17-36.75]$ & $14.4[9.6-19.5]$ & 0.995 \\
6-10 years $(\mathrm{n}=54)$ & $12.0[8.37-15.99]$ & $15.1[10.4-19.50]$ & 0.273 \\
$11-15$ years $(\mathrm{n}=211)$ & $9.5[6.82-14.17]$ & $15.1[10.4-19.5]$ & 0.134 \\
$16-18$ years $(\mathrm{n}=304)$ & $13.4[9.9-16.2]$ & $16.7[12.5-23.9]$ & 0.286 \\
\hline $\mathrm{p}<0.05$ considered statistically significant & & \\
\hline
\end{tabular}


assessment of gonadotropins and sex steroids in children in different age groups and their relationship with prolactin and thyroid hormone levels. Obesity was also not assessed among children in our study cohort and serum prolactin levels were not adjusted for childhood obesity. There is a report suggesting that serum prolactin may be lower in children with obesity (20). However, it must be highlighted that our institute is a government medical college and hospital, providing free medical treatment to the population. The majority of our patients are the off spring of parents of low socio-economic status, and obesity is rare in these children. Being a crosssectional study, the impact of levothyroxine supplementation on prolactin levels in $\mathrm{ScH}$ and overt primary hypothyroidism was not evaluated, and is a limitation.

To conclude, it may be said that hyperprolactinemia is common in children with hypothyroidism, observed in a third of children with $\mathrm{ScH}$ and in more than half of children with overt hypothyroidism. ROC analysis confirmed that a TSH $\geq 4.00 \mathrm{mIU} / \mathrm{L}$ has a good sensitivity and specificity in predicting hyperprolactinemia in children. Further longitudinal studies are warranted to evaluate the impact of this hyperprolactinemia on clinical outcomes in children and to establish if hyperprolactinemia should be considered as an indication for treating $\mathrm{ScH}$ in children.

\section{Ethics}

Ethics Committee Approval: The study was approved by the Institutional Ethics Committee of Dr. Ram Manohar Lohia Hospital and Post Graduate Institute of Medical Education and Research, New Delhi [approval number: 89 (13/2014/ IEC/PGIMER/RML/1645) dated $11^{\text {th }}$ June 2014].

Informed Consent: Consent was filled out by children and their parents/guardians.

Peer-review: Externally peer-reviewed.

\section{Authorship Contributions}

Surgical and Medical Practices: Deep Dutta, Lokesh Kumar Sharma, Concept: Deep Dutta, Design: Deep Dutta, Neera Sharma, Data Collection or Processing: Lokesh Kumar Sharma, Neera Sharma, Analysis or Interpretation: Deep Dutta, Lokesh Kumar Sharma, Literature Search: Deep Dutta, Neera Sharma, Writing: Deep Dutta, Lokesh Kumar Sharma, Neera Sharma.

Financial Disclosure: The authors declared that this study received no financial support.

\section{References}

1. Mancini T, Casanueva FF, Giustina A. Hyperprolactinemia and prolactinomas. Endocrinol Metab Clin North Am 2008;37:67-99.
2. Sharma LK, Sharma N, Gadpayle AK, Dutta D. Prevalence and predictors of hyperprolactinemia in subclinical hypothyroidism. Eur J Intern Med 2016;35:106-110.

3. Dutta D, Maisnam I, Ghosh S, Mukhopadhyay P, Mukhopadhyay S, Chowdhury S. Panhypopituitarism with empty sella a sequel of pituitary hyperplasia due to chronic primary hypothyroidism. Indian J Endocrinol Metab 2012;16:282-284.

4. Khawaja NM, Taher BM, Barham ME, Naser AA, Hadidy AM, Ahmad AT, Hamamy HA, Yaghi NA, Ajlouni KM. Pituitary enlargement in patients with primary hypothyroidism. Endocr Pract 2006;12:29-34.

5. Asa SL, Ezzat S. The pathogenesis of pituitary tumours. Nat Rev Cancer 2002;2:836-849.

6. Serri O, Chik CL, Ur E, Ezzat S. Diagnosis and management of hyperprolactinemia. CMAJ 2003;169:575-581.

7. Raber W, Gessl A, Nowotny P, Vierhapper H. Hyperprolactinaemia in hypothyroidism: clinical significance and impact of TSH normalization. Clin Endocrinol (Oxf) 2003;58:185-191.

8. Aitkenhead H, Heales SJ. Establishment of paediatric age-related reference intervals for serum prolactin to aid in the diagnosis of neurometabolic conditions affecting dopamine metabolism. Ann Clin Biochem 2013;50:156158.

9. Sharma N, Sharma LK, Dutta D, Gadpayle AK, Anand A, Gaurav K, Mukherjee S, Bansal R. Prevalence and Predictors of Thyroid Dysfunction in Patients with HIV Infection and Acquired Immunodeficiency Syndrome: An Indian Perspective. J Thyroid Res 2015;2015:517173. Epub 2015 Dec 22

10. Samson SL, Hamrahian AH, Ezzat S; AACE Neuroendocrine and Pituitary Scientific Committee; American College of Endocrinology (ACE). American Association Of Clinical Endocrinologists, American College Of Endocrinology Disease State Clinical Review: Clinical Relevance Of Macroprolactin In The Absence Or Presence Of True Hyperprolactinemia. Endocr Pract 2015;21:1427-1435.

11. Poppe K, Velkeniers B, Glinoer D. Thyroid disease and female reproduction Clin Endocrinol (Oxf) 2007;66:309-321.

12. Lu KH, Chen HI, Grandison L, Huang HH, Meites J. Reduced luteinizing hormone release by synthetic luteinizing hormone-releasing hormone (LHRH) in postpartum lactating rats. Endocrinology 1976;98:1235-1240.

13. Catli G, Abaci A, Altincik A, Demir K, Can S, Buyukgebiz A, Bober E. Hyperprolactinemia in children: clinical features and long-term results. J Pediatr Endocrinol Metab 2012;25:1123-1128.

14. Saito E, Correll CU, Gallelli K, McMeniman M, Parikh UH, Malhotra AK, Kafantaris V. A prospective study of hyperprolactinemia in children and adolescents treated with atypical antipsychotic agents. J Child Adolesc Psychopharmacol 2004;14:350-358.

15. Catli G, Abaci A, Bober E, Büyükgebiz A. Clinical and diagnostic characteristics of hyperprolactinemia in childhood and adolescence. J Pediatr Endocrinol Metab 2013;26:1-11.

16. Galli-Tsinopoulou A, Nousia-Arvanitakis S, Mitsiakos G, Karamouzis M, Dimitriadis A. Osteopenia in children and adolescents with hyperprolactinemia. J Pediatr Endocrinol Metab 2000;13:439-441.

17. Selvan C, Dutta D, Ghosh S, Mukhopadhyay S, Chowdhury S. Growth hormone deficiency, secondary hypothyroidism, and empty sella following treatment of childhood macroprolactinoma. Indian J Endocrinol Metab 2013;17:132-134.

18. Carlson HE, Jacobs LS, Daughaday WH. Growth hormone, thyrotropin, and prolactin responses to thyrotropin-releasing hormone following diethylstilbestrol pretreatment. J Clin Endocrinol Metab 1973;37:488-490.

19. Surana V, Aggarwal S, Khandelwal D, Singla R, Bhattacharya S, Chittawar S, Kalra S, Dutta D; Society for Promotion of Education in Endocrinology and Diabetes Group, India. A 2016 clinical practice pattern in the management of primary hypothyroidism among doctors from different clinical specialties in New Delhi. Indian J Endocrinol Metab 2017;21:165-177.

20. Chirico V, Cannavò S, Lacquaniti A, Salpietro V, Mandolfino M, Romeo PD, Cotta O, Munafò C, Giorgianni G, Salpietro C, Arrigo T. Prolactin in obese children: a bridge between inflammation and metabolic-endocrine dysfunction. Clin Endocrinol (Oxf) 2013;79:537544. 